\title{
Is Young Age a Limiting Factor When Training Balance? Effects of Child-Oriented Balance Training in Children and Adolescents
}

\author{
Michael Wälchli, Jan Ruffieux, Audrey Mouthon, Martin Keller, and Wolfgang Taube \\ University of Fribourg
}

\begin{abstract}
Purpose: Balance training (BT) studies in children reported conflicting results without evidence for improvements in children under the age of 8 . The aim of this study therefore was to compare BT adaptations in children of different age groups to clarify whether young age prevents positive training outcomes. Methods: The effects of 5 weeks of child-oriented BT were tested in 77 (38 girls and 39 boys) participants of different age groups (6-7 y, 11-12 y, and 14-15 y) and compared with age-matched controls. Static and dynamic postural control, explosive strength, and jump height were assessed. Results: Across age groups, dynamic postural sway decreased $\left(-18.7 \% ; P=.012 ; \eta_{\mathrm{p}}^{2}=.09\right)$ and explosive force increased $(8.6 \% ; P=.040$; $\left.\eta_{\mathrm{p}}^{2}=.06\right)$ in the intervention groups. Age-specific improvements were observed in dynamic postural sway, with greatest effects in the youngest group $(-28.8 \% ; P=.026 ; r=.61)$. Conclusion: In contrast to previous research using adult-oriented balance exercises, this study demonstrated for the first time that postural control can be trained from as early as the age of 6 years in children when using child-oriented BT. Therefore, the conception of the training seems to be essential in improving balance skills in young children.
\end{abstract}

Keyword: postural control, explosive strength, jump height, training content

Balance training (BT) can improve postural control. This has recently been confirmed in systematic reviews for older adults (21) and healthy young adults (20). In addition, there are several studies demonstrating that BT interventions lead to improved postural control in children/adolescents aged older than 12 years $(4,17,25,38)$. However, evidence that postural control can be improved by means of BT in younger children is much weaker.

It is well established that the postural control system is developing during childhood and adolescence, with a strong reorganization at the age of about 6 years (28). Young children rely predominantly on the visualvestibular system to maintain balance (19), while they start to change toward a more somatosensory-vestibular control at around the age of 6 (31). However, this transition to an adult-like balance control is not yet completed at the age of $12(2,26)$. In addition, hierarchical lower-level systems of postural control (ie, reflexes) are already present at birth, whereas supraspinal systems mature later and do not show adult-like behavior

Wälchli, Ruffieux, Mouthon, Keller, and Taube are with the Dept. of Medicine, Movement and Sport Sciences, University of Fribourg, Fribourg, Switzerland. Address author correspondence to Michael Wälchli at michael.waelchli@unifr.ch. until a child is about 10 years old (3). It may be speculated that young children rely on a premature postural control system and, therefore, respond differently to BT than older children or adolescents. As there is increasingly more evidence that supraspinal centers are largely responsible for BT-induced improvements (35), the immaturity of the supraspinal system may prevent an improvement in postural control in young children. It might, therefore, be assumed that the age (or the developmental stage) plays an important role for the acquisition and the transfer of balance skills in childhood and adolescence.

To our knowledge, only 3 studies have investigated the impact of BT on stance stability in children aged younger than 12 years. When considering the youngest participants aged 6-7 years, several weeks of BT using unstable support surfaces with a predefined number of sets and durations (ie, classical BT) did not provoke any improvements in postural stability (13), although this kind of training is known to be beneficial in elite athletes (36), young adults (34), and older adults (11). When applying slackline training in older children aged around 10 years, Donath et al (8) did indeed observe task-specific improvements on the slackline. However, no improvements in transfer (ie, untrained) balance tests have been detected. Improved postural control in 
transfer balance tests has been demonstrated after inline skating (22) with children aged around 11 years. Furthermore, there are several studies demonstrating improved postural control in trained and untrained postural tasks after BT interventions in children/adolescents aged older than 12 years $(4,17,25,38)$. Thus, it seems that with advancing of age, the beneficial effect of BT is increasing.

Apart from the children's age, the BT intervention content may greatly influence the outcome on postural control. It was previously assumed that classical BT in intervention form is rather inappropriate for young children (13). The authors assumed that classical BT did not sufficiently motivate young children to participate with any great effort, as active participation of the children was observed only when they were directly supervised by the teacher. It is, therefore, not clear whether the content of the BT or the age of the children was responsible for the divergent results in previous BT studies with young children. To clarify this issue, the present study applied child-oriented BT (for a detailed description, see "Methods" section) in 3 different age groups (6-7 y, 11-12 y, and 14-15 y). The applied childoriented BT was, in particular, developed with the aim to increase children's motivation during the intervention by providing favorable challenges for every participant. This means that different levels of difficulty were provided for each exercise, and that exercises and activities were frequently modified and adapted to avoid monotonous repetitions. Furthermore, participants were allowed in some activities to make their own choices on how to manage a given task $(1,18)$.

The aim of the study was, therefore, to test whether postural control can be improved by means of childoriented BT in young children as early as the age of 6 and to compare their training-induced adaptations with those of older children and adolescents. In addition, jump performance and explosive strength were analyzed, as it has been shown previously that BT can improve jump height and explosive force in adults (35). We hypothesized that older children/adolescents would benefit more from the child-oriented BT, as they use a more mature postural control strategy.

\section{Methods}

The realization of the present study was approved by the local ethics committee (87/14). All parents and children were thoroughly informed, and written consent was obtained from parents and children aged over 10 years. The experimental protocol respected the latest ethical principles for medical research involving human subjects of the Declaration of Helsinki.

\section{Participants}

A total of 77 children of 3 different age groups (Y: young, 6-7 y; M: middle, 11-12 y; O: old, 14-15 y) participated in this study (see Table 1). Each age group consisted of an intervention group (INT; regular school classes) and a control group (CON). The regular school class for the O-INT consisted of 15 pupils who all participated and completed the experiment. In the MINT, 19 pupils started the procedure, but only 18 finished the intervention due to an injury 1 child suffered in the leisure time. In the school class with the youngest aged pupils, 15 out of 20 pupils volunteered to participate in this study. The children for the CON groups originated from different schools in the same region. None of the participants or parents reported neurological/orthopedic diseases or motor difficulties. In a few cases, because of the difficulty of some tests, or errors in data recording, not all of the 77 participants were included.

\section{Training Intervention}

The BT was held during physical education lessons and lasted for 5 weeks with 2 sessions per week (45 min/ session). Each session started with a warm up (10 min) containing small games related to postural control. For the main part of the lesson (35 min), a special topic was selected for each week (see Table 2). All intervention lessons were guided by a supervisor and the regular school teacher to keep the pupil to teacher ratio low.

Importantly, the child-oriented BT differed from the classical BT [for a definition of classical BT, see (14)], as previous research suggested that classical BT may not be adequate for children (13). Children's participation in

Table 1 Anthropometric Data of INT and CON Groups for the Different Age Groups (Young, Middle, and Old)

\begin{tabular}{|c|c|c|c|c|c|c|}
\hline & \multicolumn{2}{|c|}{ Young } & \multicolumn{2}{|c|}{ Middle } & \multicolumn{2}{|c|}{ Old } \\
\hline & INT & CON & INT & CON & INT & CON \\
\hline$N$ & 15 & 10 & 18 & 9 & 15 & 10 \\
\hline Gender, f/m & $8 / 7$ & $4 / 6$ & $7 / 11$ & $4 / 5$ & $9 / 6$ & $6 / 4$ \\
\hline Age, y & $6.2(0.4)$ & $6.2(0.8)$ & $11.4(0.5)$ & $11.4(0.7)$ & $14.1(0.5)$ & $14.9(0.8)$ \\
\hline Weight, kg & $23.0(4.3)$ & $22.5(3.4)$ & $47.9(11.2)$ & $39.5(5.7)$ & $56.3(9.1)$ & $65.8(12.3)$ \\
\hline Height, $\mathrm{cm}$ & $119.5(6.5)$ & 122.5 (11.9) & $154.3(5.7)$ & $150.1(4.9)$ & $163.4(9.0)$ & $168.7(10.4)$ \\
\hline
\end{tabular}

Note. Values for age, weight, and size are indicated as group mean $(S D)$. In some cases, not all of the 77 participants could be included.

Abbreviations: CON, control; f, female; INT, intervention; m, male. 
Table 2 Content of the Training Intervention Program Developed for Children and Adolescents (ie, Child-Oriented BT)

\begin{tabular}{|c|c|c|}
\hline Training & Topic & Content \\
\hline 1 and 2 & Balance circuit & $\begin{array}{l}\text { Children executed different balance exercises, such as walking over bars, } \\
\text { moving forward with a Pedalo, walking on a ball, that is, between } 2 \text { mats or } \\
\text { standing on a mat on free-moving balls. The aim was to explore and modify the } \\
\text { exercises by themselves and at the end to execute the exercises for as long/far as } \\
\text { possible. }\end{array}$ \\
\hline 3 and 4 & Parkour 1 & $\begin{array}{l}\text { Children had to explore a way to cross over different (unstable) obstacles and to } \\
\text { accomplish predefined routes without touching the ground. }\end{array}$ \\
\hline 5 and 6 & Parkour 2 & $\begin{array}{l}\text { Children had to explore a way to cross over newly defined (unstable) obstacles } \\
\text { and to accomplish predefined routes without touching the ground. }\end{array}$ \\
\hline 7 and 8 & Competitive balance games 1 & $\begin{array}{l}\text { Children were asked to make their opponent lose balance in different situations, } \\
\text { such as hopping on } 1 \mathrm{leg} \text {, standing on a small surface, standing on wobbling } \\
\text { surfaces, etc. }\end{array}$ \\
\hline 9 and 10 & Competitive balance games 2 & $\begin{array}{l}\text { Children competed against each other or tried to outperform their previous } \\
\text { scores in different balance exercises. The organization form was varied ( } 1 \\
\text { against } 1,2 \text { against 2, groups against each other, echelons, etc). }\end{array}$ \\
\hline
\end{tabular}

Note. Each topic was treated in 2 sessions of 45 minutes each. The listed content represents only a short summary of the main parts of the lessons. In each lesson, multiple exercises on different balance devices were executed in variable forms to provide a constant challenge for the pupils.

Abbreviation: BT, balance training.

physical education was assumed to be enhanced by promoting intrinsic motivation (1). For this purpose, the intervention consisted of 3 different topics, starting with a balance circuit, followed by 2 Parkour lessons, and finally ending with competitive balance games (childoriented BT; see Table 2). The aim of the balance circuit was to provide a variety of different balance exercises with adjustable levels of difficulty to appropriately challenge all children/adolescents. Then, the following Parkour lessons were designed to foster the freedom of choice by engaging the participants to explore their own way and techniques to balance over the (unstable) obstacles. And, finally, the competitive balance games challenged participants to perform balance exercises for as long/good as possible. For this purpose, performances were regularly compared with other participants or with own previous results (18). The balance exercises and the specific instructions were tested in a prestudy in 3 other school classes with children and adolescents of similar age (6-7 y, 11-12 y, and 14-15 y). Participation was captured by analyzing the activity time during physical education sessions. Participants' mean activity time in the prestudy was above the recommended $50 \%$ of total lesson time (37) for all of the 10 developed sessions. In addition, the activity time in all age groups during exercises at the end of the sessions was not decreased compared with exercises at the beginning of the sessions, indicating that the willingness of participation was high until the end of the BT.

All participants of the CON groups followed regular physical education lessons during the 5 weeks between pretest and posttest. The amount of physical education was, therefore, identical for INT and CON groups. The CON groups worked on common physical education topics (no specific BT exercises), whereas the INT groups exclusively worked on postural control.

\section{Measurements}

Premeasurements for the INT group took place in the week before the training started. Similarly, postmeasurements were assessed in the week after the training was completed. The same procedure was considered for participants of the CON groups.

Balance Tests on the Force Plate. Center of pressure (COP) measurements on the force plate $(508 \times 464 \mathrm{~mm}$; OR6-7 Force Platform; Advanced Mechanical Technology Inc, Watertown, MA), which have previously been shown to be reliable in analyzing balancing abilities (24), were used to evaluate balance tests with different test difficulties (ie, static and dynamic, double- and single-leg stance) to cover a wide range of postural control levels. Before recording, participants performed 2 repetitions in double- and single-leg (right leg) stance for 15 seconds, to become familiar with the spinning top (Pedalo Kreisel Pro-Pedes, ø: $27 \mathrm{~cm}$, height: $4.9 \mathrm{~cm}$; Holz-Hoerz GmbH, Münsingen, Germany). After the familiarization phase, data acquisition started with 3 static balance tests: tandem stance (feet on a line and right foot in front), Romberg stance (feet parallel and in touch), and Romberg stance with eyes closed. Subsequently, 2 dynamic balance tests were executed: doubleand single-leg (right leg) stance on the spinning top.

For each test, participants were instructed to stand as quiet as possible for 15 seconds on the force plate with their arms akimbo and with visual fixation on a cross marked on the wall. Each test was repeated twice with a pause of 1 minute between trials and 2 minutes between different tests. The short recording time and the few repetitions were chosen due to the fact that concentration of children/ adolescents is limited in time. To stand as quiet as possible demands high levels of concentration and prohibits any voluntary movements, which was particularly hard for the 
youngest group to accomplish for over 15 seconds. If a participant moved the foot or stumbled during data acquisition, a third trial was recorded (maximal 3 trials per test). Data were recorded at $1 \mathrm{kHz}$ with custom-built software (LabVIEW based; National Instruments Corporation, Austin, TX) and analyzed offline in MATLAB (R2015a; the MathWorks Inc, Natick, MA). After applying a low-pass filter $(10 \mathrm{~Hz})$, the $x$ - and $y$-coordinates of the COP were calculated with the equations: $x=\frac{-h F_{x}-M_{y}}{F_{z}}$ and $y=\frac{-h F_{y}+M_{x}}{F_{z}}$, respectively, where $h$ corresponds to the distance between the feet and the force plate. For the first 3 tests, $h$ was defined as $0 \mathrm{~cm}$ because subjects stood directly on the force plate. For the tests with the spinning top, $h$ was defined as the height of the spinning top $(4.9 \mathrm{~cm})$. The coordinates $x$ and $y$ were used to generate a stabilogram, and the COP sway was calculated by summing the distance between the points of the stabilogram (ie, COP sway per $15 \mathrm{~s}$ ). For each test, only the best trial was used for further analysis because of the high variability between trials. Three participants of Y-INT and 2 participants of Y-CON had to be excluded in the single-leg stance on the spinning top, as they were not able to maintain the correct position for 15 seconds.

Balance Test on the Free-Swinging Platform. A 2dimensional free-swinging platform (Posturomed; Haider Bioswing, Pullenreuth, Germany) was used to assess balance in a dynamic stabilization task (23). After 2 familiarization trials on the platform in double- and single-leg (right leg) stance for 15 seconds, all participants started with 3 consecutive double-leg stance trials followed by 3 single-leg trials. Test instructions and pauses between trials and series were similar to the tests on the force plate. If 1 trial was not executed correctly, 1 additional trial was recorded. Two reflecting markers were fixed on the platform to capture the sway of the platform with a Vicon 512 system (Vicon Motion Systems Ltd, Oxford, UK). Data were sampled at $120 \mathrm{~Hz}$ with Vicon software and analyzed offline with MATLAB. For both tests, the best trial was used for further analysis. Two participants of the O-INT had to be excluded in the single-leg stance on the freeswinging platform due to incomplete data acquisition.

Countermovement Jump. After a short warm up (jogging and hopping), participants performed countermovement jumps (CMJ) on the force plate. Participants were instructed to jump with their arms akimbo as high as possible, with maximum effort in each jump. After 2 jumps for familiarization, $6 \mathrm{CMJ}$ were recorded with a break of 10 seconds between jumps. Vertical ground reaction forces from the force plate were sampled at $1 \mathrm{kHz}$ and analyzed offline with MATLAB. Values below $5 \mathrm{~N}$ were considered to represent the flight phase. Jump height was calculated by the formula: jump height $=1 / 8 \times g \times t^{2}$, where $g$ is the acceleration due to gravity and $t$ represents the duration of the flight phase. The best out of the $6 \mathrm{CMJ}$ was used for further analysis. One participant of O-CON had to be excluded from this test.

Explosive Strength. Explosive strength of the plantar flexor muscles was assessed by determining the maximal rate of torque development (RTD). For this purpose, participants were in a supine position with straight legs and the right foot tightly fixed to an isokinetic dynamometer (Humac Norm; Computer Sports Medicine Inc, Stoughton, MA). The axis of the ankle joint was exactly aligned with the axis of the dynamometer. The lower leg was fixed to the seat by a large strap to avoid contribution from knee or hip extensors. Data were recorded during isometric contractions in a neutral ankle joint position. Participants were instructed to execute the plantar flexion as fast as possible. The measurement contained 3 trials for familiarization followed by $2 \times 10$ trials. A pause of 6 seconds between 2 consecutive trials and of 3 minutes between the 2 sets was given. Sampling frequency for RTD data was set at $1 \mathrm{kHz}$. The maximal RTD was determined offline in MATLAB selecting the 10-ms window with the largest increase in torque. The value of the best trial was used for further analysis. Due to incomplete data acquisition, 3 participants of O-INT could not be included in the analysis.

\section{Statistics}

Changes in balance performance were analyzed using a 3way mixed design repeated measures analysis of variance with the within-subject factor time (pre vs post) and the between-subject factors group (INT vs CON) and age (Y vs $\mathrm{M}$ vs $\mathrm{O})$. In the case of significant $F$ values $(P<.05)$, a post hoc analysis with Bonferroni-corrected Student's $t$ tests was applied to determine significant differences between factors level. Furthermore, effect sizes of analyses of variance are presented as partial eta square values $\left(\eta_{\mathrm{p}}^{2}\right.$; small effect: .02; medium effect: .13; and large effect: .26) and for Student's $t$ tests as Pearson correlation coefficient ( $r$; small effect: .10; medium effect: .30; large effect: .50). IBM SPSS Statistics for Windows software (version 23; IBM Corp, Armonk, NY) was used for all statistical analyses. Data are presented as mean and standard error if not otherwise indicated.

\section{Results}

\section{Age}

The 3-way mixed design analysis of variance with repeated measures revealed a significant effect for the factor age in all measured postural control parameters, in RTD, and in CMJ. Post hoc analyses showed significant differences between the $\mathrm{Y}$ and the 2 older groups ( $\mathrm{M}$ and O) for each parameter, indicating that performances of the youngest group were significantly lower compared with the older groups. No differences were found between $\mathrm{M}$ and $\mathrm{O}$ except for $\mathrm{RTD}(P<.001 ; r=.57)$, where the oldest group generated higher values than $\mathrm{M}$.

\section{Training Adaptations}

Significant time $\times$ group interactions were found for tandem stance $\left(F_{1,71}=4.085 ; P=.047 ; \eta_{\mathrm{p}}^{2}=.05\right)$, single- 


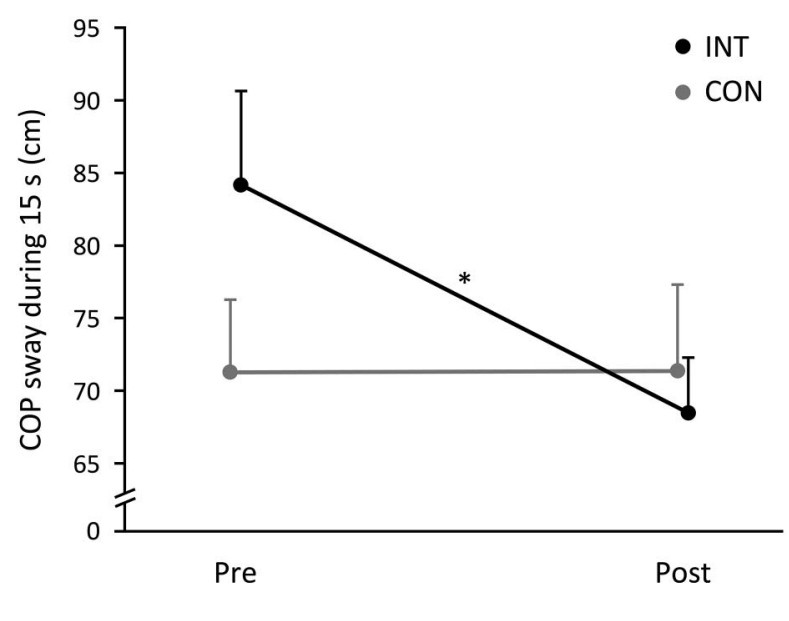

Figure 1 - COP sway for single-leg stance on the spinning top (interaction: $P=.012 ; \eta_{\mathrm{p}}^{2}=.09$; INT: $r=.45$ ). Black dots and lines represent all INT groups and gray dots and lines represent all CON groups. COP indicates center of pressure; INT, intervention; CON, control. ${ }^{*} P=.012$.

leg stance on the spinning top $\left(F_{1,66}=6.652\right.$; $P=.012 ; \eta_{\mathrm{p}}^{2}=.09$; see Figure 1$)$, and RTD $\left(F_{1,68}=\right.$ $4.375 ; P=.040 ; \eta_{\mathrm{p}}^{2}=.06$; see Figure 2). Post hoc analyses of tandem stance revealed no significant changes for either INT or CON over time. In contrast, children of the INT group improved significantly from pretest to posttest in the single-leg stance on the spinning top $(18.7 \% ; P=.002 ; r=.45)$, whereas performance of the CON group did not change $(-0.1 \% ; P=.985 ; r<.01$; see Figure 1). Figure 1 displays better initial balance performances (pretest) for CON groups compared with INT groups. However, this difference is statistically not significant $(P=.167 ; r=.16)$. Positive adaptations in response to BT can also be reported for RTD, where the explosive strength of the INT increased significantly $(8.6 \% ; P=.024 ; r=.33)$, whereas there was no significant change in the CON group $(-3.5 \% ; P=.409 ; r=.16$; see Figure 2). In all other measured parameters, no significant time $\times$ group interactions could be determined. In this context, it has to be noted that the time $\times$ group interaction for single-leg stance on the free-swinging platform failed to reach significance due to improved performance in both the INT and the CON groups (see Figure 3B).

\section{Age-Specific Adaptations}

Statistical analyses revealed significant time $\times$ group $\times$ age interactions for single-leg stance on the spinning top $\left(F_{2,66}=3.217 ; P=.046 ; \eta_{\mathrm{p}}^{2}=.09\right.$; see Figure $\left.3 \mathrm{~A}\right)$ and for single-leg stance on the free-swinging platform $\left(F_{2,69}=\right.$ $4.069 ; P=.021 ; \eta_{\mathrm{p}}^{2}=.11$; see Figure $3 \mathrm{~B}$ ). Post hoc testing of single-leg stance on the spinning top indicated significant improvements for Y-INT $(P=.026 ; r=.61)$ and for M-INT $(P=.006 ; r=.60)$, whereas for O-INT $(P=.274 ; r=.29)$ and for all CON groups, no significant changes from pretest to posttest were observed.

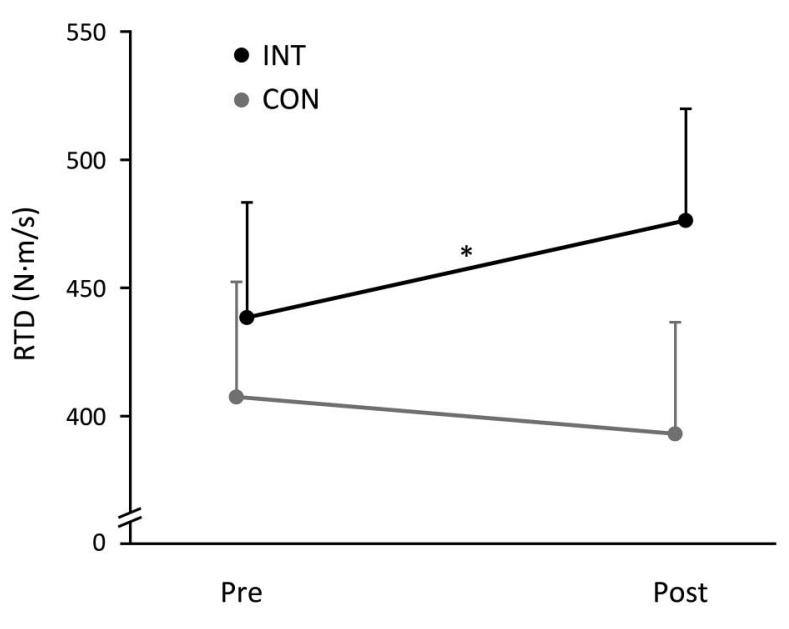

Figure 2 - RTD for explosive strength test in an isometric right-leg plantar flexion (interaction: $P=.040 ; \eta_{\mathrm{p}}^{2}=.06$; INT: $r=.33$ ). Black dots and lines represent all INT groups and gray dots and lines represent all CON groups. RTD, rate of torque development; INT, intervention; CON, control. $* P=.040$.

Interestingly, the largest improvement in this postural control task could be detected in Y-INT $(28.8 \%)$. The older groups followed with $13.5 \%$ (M-INT) and $8.4 \%$ (O-INT) demonstrating positive adaptations in response to child-oriented BT, particularly in the youngest children. Post hoc analyses for single-leg stance on the freeswinging platform showed substantial improvements in Y-INT $(P=.001 ; r=.73)$ and O-INT $(P=.017 ; r=.63)$, but no performance gains for M-INT $(P=.096 ; r=.39)$. Platform sway reductions in single-leg stance were not exclusively observed for the INT groups but were also seen in the CON groups, M-CON $(P=.048 ; r=.64)$ and O-CON $(P=.034 ; r=.64)$ on the free-swinging platform. The reductions of $34.7 \%$ for $\mathrm{M}-\mathrm{CON}$ and $31.2 \%$ for O-CON in the platform sway path in single-leg stance were smaller than in Y-INT (54.7\%), but larger than in O-INT (27.8\%) and M-INT (21.8\%). Post hoc analyses of pretest performances between INT and CON for each age group revealed no significant differences in singleleg stance on the spinning top (Y: $P=.088 ; r=.39$, M: $P=.444 ; r=.15$, O: $P=.703 ; r=.08$; see Figure $3 \mathrm{~A})$ and single-leg stance on the free-swinging platform $(\mathrm{Y}$ : $P=.163 ; r=.29$, M: $P=.493 ; r=.14$, O: $P=.144 ; r=$ .31 ; see Figure $3 \mathrm{~B})$. No age-specific adaptations were detected for RTD $\left(F_{2,68}=0.534 ; P=.589 ; \eta_{\mathrm{p}}^{2}=.01\right)$, indicating that RTD was similarly increased in the 3 different age groups that underwent child-oriented BT.

\section{Discussion}

The current results are important to highlight that balance skills can be successfully trained in children, at least from the age of 6 . Previous studies implementing balance interventions in children and adolescents were heterogeneous in terms of age and training content, and 

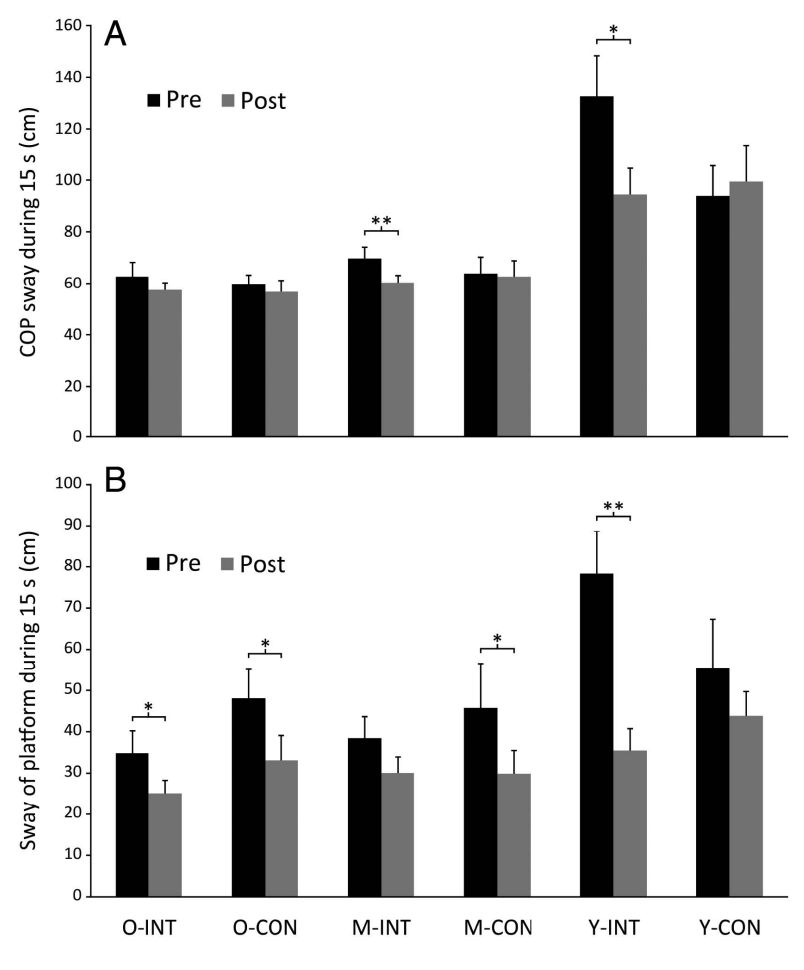

Figure 3 - (A) COP sway for single-leg stance on the spinning top (interaction: $P=.046 ; \eta_{\mathrm{p}}^{2}=.09 ; \mathrm{Y}$-INT: $r=.61$; M-INT: $r=.60$ ). (B) Sway of platform for single-leg stance on the free-swinging platform (interaction: $P=.021 ; \eta_{\mathrm{p}}^{2}=.11$; $\mathrm{Y}-$ INT: $r=.73$; O-INT: $r=.63$; M-CON: $r=.64$; O-CON: $r$ $=.64$ ). Black bars represent pretest values and gray bars represent posttest values. $\mathrm{COP}$ indicates center of pressure; INT, intervention; CON, control; Y, young; M, middle; O, old. $* P<.05 . * * P<.01$.

revealed ambiguous results without clear evidence for a positive effect of BT on postural control. Notably, this is the first study showing positive effects of BT in young children. This may be surprising, as it is well known that BT promotes postural control in young (20) and older adults (21).

\section{Postural Control and Explosive Strength Across Ages}

Postural control $(10,28)$ and force abilities (27) develop with increasing age and do not achieve peak values before early adulthood $(5,16)$. Although the youngest group in the present study clearly showed the worst performance in all tests, the difference between the 2 older groups was small or even nonexistent. In postural control and jump tasks, no statistical differences between $\mathrm{M}$ and $\mathrm{O}$ were detected. However, RTD differed significantly among all age groups, indicating that explosive strength and postural control do not develop in parallel in children/adolescents. Our results, therefore, support the assumption that force is continuously and considerably increasing during childhood (7), whereas postural control seems to mature predominantly between the age of 6 and $11(6,29)$, and only marginally from 11 to 14 years (2). In line with this, an adult-like balance control can usually be seen around the age of 12-14 years $(2,26)$. As mentioned previously, the postural control system undergoes a profound reorganization process starting at around the age of 6 (28). The youngest group of the present study was at the beginning of this reorganization process and was probably using other mechanisms to control balance than the older participants. As the 2 older groups showed comparable balance performances, we assume that these groups relied on similar and more mature postural control strategies.

\section{Training Adaptations}

Previous BT studies in children younger than 12 years reported either no effects on postural control (13), taskspecific adaptations only (8), or even improved postural control in transfer tasks (22). However, comparisons between those studies are hardly possible, as not only the age of the participants greatly differed but also the training content. Therefore, the first step in evaluating the current training adaptations is to assess the impact of the childoriented BT in general, that is, across all 3 age groups. When analyzing all 3 INT groups together, dynamic balance was improved. In addition, explosive strength was significantly increased from pretest to posttest in the INT groups. Although in young adults increases in explosive strength after BT have repeatedly been reported (for review, see 35), this is the first study demonstrating that BT can improve explosive strength in children and adolescents.

Apart from these general effects across all age groups, we also observed age-related training adaptations in postural control. Based on previous studies showing no or only limited adaptations in young children after BT $(8,13)$, it was hypothesized that older children/adolescents would benefit more from the intervention, probably due to their more matured postural control system. However, the youngest group improved to a larger extent than the 2 older groups that showed similar performance adjustments. The reason for this greater improvement in the youngest group of children might be due to their lower level of postural control at baseline. Thus, young children had a larger range of improvement available, whereas ceiling effects might have limited improvements in the 2 older groups. Alternatively, it could be argued that the immaturity of the balance control system in children has a greater adaptive reserve and might, therefore, adapt more quickly. However, to answer this question, balance tests need to be developed that allow a continuous (linear) progression of difficulty that can be quantified. Nevertheless, although we cannot answer why the youngest group displayed the largest training effects, the present results point out that the age — or the immature postural control system-is not a limiting factor for BT-induced improvements in young children.

\section{Training Content}

Previous BT interventions with healthy children differed quite clearly from one another. The first training 
intervention applied in young children was classical BT. According to the authors, this kind of training did not sufficiently motivate the children to active participation (13). Subsequent studies applied other training contents, such as inline skating (22) or slacklining (8). The former provoked improvements in postural transfer tasks, whereas the latter reported only task-specific improvements on the slackline, even though the training schedule incorporated daily training sessions of 10 minutes with only a small number of children (2-3 children). However, it has to be noted that when considering slackline training in general, behavioral adaptations seem to be specific to the slackline, with little or no transfer to other balance tasks $(9,12)$. In contrast, the present results demonstrate that child-oriented BT leads to improvements in postural (transfer) tasks in children from the age of 6 onward. The child-oriented BT was designed to highly motivate the children for the balance intervention. To test the compliance in the child-oriented BT, activity time was measured in a prestudy and was shown to be higher than the recommended value of $50 \%$ of total lesson time (37). In addition, the supervisors of the training reported the persistent interest and willingness of the children and adolescents to participate in the training sessions with great dedication and effort. All teachers and supervisors considered the training intervention to be adequate for children and adolescents. It may, therefore, be assumed that the child-oriented tailoring of the BT was essential to get the participants highly involved in the training process, probably the most important prerequisite for positive training adaptations. Consequently, great emphasis should be placed on the training content to improve postural control in (young) children and adolescents.

\section{Limitations}

No improvements from pretest to posttest were found when assessing balance in static conditions. We assume that the static tests were not difficult enough to detect any improvements. Similarly, 2 dynamic tests in which children were standing on both legs were probably not difficult enough to identify performance gains. This finding has previously been reported for healthy seniors after an inline skating intervention (33), where the magnitude of training adaptation correlated with balance test difficulty. It was further observed that patients with Parkinson's disease may perform static balance tests even more steadily than healthy persons, but as soon as the difficulty level of the balance test was increased, patients with Parkinson's disease clearly displayed more sway $(15,30,32)$. This illustrates that less-demanding balance tests are often unsuitable to detect improvements or differences in postural control. For the present study, the level of difficulty for the postural control tests was chosen to be rather low so that the 6-year-old children could also successfully accomplish them (ie, avoiding floor effects). As the range of task difficulty for training gain detection is probably small—due to ceiling effects for facile tests and floor effects for difficult tests-the postural challenge might have been too low for the older age groups in the current study. Thus, the ceiling effects might have prevented greater adaptations in the 2 older groups. To counteract this limitation, future studies should apply tests with adjustable difficulty levels.

Significantly reduced sway paths for $2 \mathrm{CON}$ groups ( $\mathrm{M}$ and $\mathrm{O}$ ) were found in the single-leg stance on the free-swinging platform. Although several familiarization trials were performed before the first measurement, it might be assumed that pretesting on the free-swinging platform - which was a novel device for all participants -still elicited learning effects that led to improved performance in the posttest.

\section{Conclusion}

The present study provides evidence that postural control in transfer tasks and explosive strength can be improved in children and adolescents by applying child-oriented BT. Age-specific training adaptations were found, with greatest gains in the youngest group. We assume that the lower performance level of the young children led to this greater improvement. More importantly, we have shown that the young age-and, thus, the immaturity of the postural control system-did not prevent positive adaptations. To the best of our knowledge, this is the first study demonstrating that postural control can be trained by means of BT from as early as 6 years old. The fundamental prerequisite for this seems to be the content of the BT, which should be tailored to the needs of children and adolescents.

\section{Acknowledgments}

The authors would like to thank Ranjith Sivagnanaselvam, Stefanie Strahm, Matthias Neuhaus, Pascal Haab, and Luca Fischer for their support. The authors declare no conflicts of interest. This work was supported by the Swiss Federal Office of Sports (grant number 14-06).

\section{References}

1. Alderman BL, Beighle A, Pangrazi RP. Enhancing motivation in physical education. $J$ Phys Educ Recreat Dance. 2006;77(2):41-51. doi:10.1080/07303084.2006.10597828

2. Barozzi S, Socci M, Soi D, et al. Reliability of postural control measures in children and young adolescents. Eur Arch Otorhinolaryngol. 2014;271(7):2069-77. PubMed doi:10.1007/s00405-014-2930-9

3. Bawa P. Neural development in children: a neurophysiological study. Electroencephalogr Clin Neurophysiol. 1981;52(4):249-56. PubMed doi:10.1016/0013-4694 (81)90054-7

4. Boccolini G, Brazzit A, Bonfanti L, Alberti G. Using balance training to improve the performance of youth basketball players. Sport Sci Health. 2013;9(2):37-42. PubMed doi:10.1007/s11332-013-0143-z 
5. Bosco C, Komi PV. Influence of aging on the mechanical behavior of leg extensor muscles. Eur J Appl Physiol Occup Physiol. 1980;45(2-3):209-19. PubMed doi:10. 1007/BF00421329

6. Cuisinier R, Olivier I, Vaugoyeau M, Nougier V, Assaiante C. Reweighting of sensory inputs to control quiet standing in children from 7 to 11 and in adults. PLoS ONE. 2011;6(5):e19697. PubMed doi:10.1371/journal. pone. 0019697

7. De Ste Croix MBA, Deighan MA, Armstrong N. Assessment and interpretation of isokinetic muscle strength during growth and maturation. Sports Med. 2003; 33(10):727-43. PubMed doi:10.2165/00007256200333100-00002

8. Donath L, Roth R, Rueegge A, Groppa M, Zahner L, Faude O. Effects of slackline training on balance, jump performance \& muscle activity in young children. Int $J$ Sports Med. 2013;34(12):1093-8. PubMed doi:10.1055/ s-0033-1337949

9. Donath L, Roth R, Zahner L, Faude O. Slackline training and neuromuscular performance in seniors: a randomized controlled trial. Scand J Med Sci Sports. 2016;26(3):27583. PubMed doi:10.1111/sms.12423

10. Gouleme N, Ezane MD, Wiener-Vacher S, Bucci MP. Spatial and temporal postural analysis: a developmental study in healthy children. Int J Dev Neurosci. 2014;38:169-77. PubMed doi:10.1016/j.ijdevneu.2014.08.011

11. Granacher U, Gollhofer A, Strass D. Training induced adaptations in characteristics of postural reflexes in elderly men. Gait Posture. 2006;24(4):459-66. PubMed doi:10.1016/j.gaitpost.2005.12.007

12. Granacher U, Iten N, Roth R, Gollhofer A. Slackline training for balance and strength promotion. Int J Sports Med. 2010;31(10):717-23. PubMed doi:10.1055/s-00301261936

13. Granacher U, Muehlbauer T, Maestrini L, Zahner L, Gollhofer A. Can balance training promote balance and strength in prepubertal children? J Strength Cond Res. 2011;25(6):1759-66. PubMed doi:10.1519/JSC. 0b013e3181da7886

14. Gruber M, Gruber SBH, Taube W, Schubert M, Beck SC, Gollhofer A. Differential effects of ballistic versus sensorimotor training on rate of force development and neural activation in humans. J Strength Cond Res. 2007; 21(1):274-82. PubMed doi:10.1519/00124278200702000-00049

15. Horak FB, Nutt JG, Nashner LM. Postural inflexibility in parkinsonian subjects. J Neurol Sci. 1992;111(1):46-58. PubMed doi:10.1016/0022-510X(92)90111-W

16. Hytönen M, Pyykkö I, Aalto H, Starck J. Postural control and age. Acta Otolaryngol. 1993;113(2):119-22. PubMed doi:10.3109/00016489309135778

17. Keller M, Röttger K, Taube W. Ice skating promotes postural control in children. Scand J Med Sci Sports. 2014;24(6):e456-61. PubMed doi:10.1111/sms.12230

18. Kilpatrick M, Hebert E, Jacobsen D. Physical activity motivation: a practitioner's guide to self-determination theory. J Phys Educ Recreat Dance. 2002;73(4):36-41. doi:10.1080/07303084.2002.10607789
19. Lee DN, Aronson E. Visual proprioceptive control of standing in human infants. Percept Psychophys. 1974; 15(3):529-32. doi:10.3758/BF03199297

20. Lesinski M, Hortobágyi T, Muehlbauer T, Gollhofer A, Granacher U. Dose-response relationships of balance training in healthy young adults: a systematic review and meta-analysis. Sports Med. 2015;45(4):557-76. PubMed doi:10.1007/s40279-014-0284-5

21. Lesinski M, Hortobágyi T, Muehlbauer T, Gollhofer A, Granacher U. Effects of balance training on balance performance in healthy older adults: a systematic review and meta-analysis. Sports Med. 2015;45(12):1721-38. PubMed doi:10.1007/s40279-015-0375-y

22. Muehlbauer T, Kuehnen M, Granacher U. Inline skating for balance and strength promotion in children during physical education. Percept Mot Skills. 2013;117(3): 665-81. PubMed doi:10.2466/30.06.PMS.117x29z9

23. Müller O, Günther M, Krauß I, Horstmann T. Physical characterization of the therapeutic device posturomed as a measuring device - presentation of a procedure to characterize balancing ability. Biomed Eng. 2004;49(3): 56-60. doi:10.1515/BMT.2004.011

24. Palmieri RM, Ingersoll CD, Stone MB, Krause BA. Center-of-pressure parameters used in the assessment of postural control. J Sport Rehabil. 2002;11(1):51-66. doi:10.1123/jsr.11.1.51

25. Pau M, Loi A, Pezzotta MC. Does sensorimotor training improve the static balance of young volleyball players? Sports Biomech. 2012;11(1):97-107. PubMed doi:10. 1080/14763141.2011.637126

26. Peterson ML, Christou E, Rosengren KS. Children achieve adult-like sensory integration during stance at 12-years-old. Gait Posture. 2006;23(4):455-63. PubMed doi:10.1016/j.gaitpost.2005.05.003

27. Rarick GL, Smoll FL. Stability of growth in strength and motor performance from childhood to adolescence. Hum Biol. 1967;39(3):295-306. PubMed

28. Riach CL, Hayes KC. Maturation of postural sway in young children. Dev Med Child Neurol. 1987;29(5):650-8. PubMed doi:10.1111/j.1469-8749.1987.tb08507.x

29. Rival C, Ceyte H, Olivier I. Developmental changes of static standing balance in children. Neurosci Lett. 2005;376(2):133-6. PubMed doi:10.1016/j.neulet.2004. 11.042

30. Schieppati M, Hugon M, Grasso M, Nardone A, Galante M. The limits of equilibrium in young and elderly normal subjects and in parkinsonians. Electroencephalogr Clin Neurophysiol. 1994;93(4):286-98. PubMed doi:10.1016/ 0168-5597(94)90031-0

31. Shumway-Cook A, Woollacott MH. The growth of stability: postural control from a development perspective. J Mot Behav. 1985;17(2):131-47. PubMed doi:10.1080/ 00222895.1985 .10735341

32. Smithson F, Morris ME, Iansek R. Performance on clinical tests of balance in Parkinson's disease. Phys Ther. 1998;78(6):577-92. PubMed doi:10.1093/ptj/78.6.577

33. Taube W, Bracht D, Besemer C, Gollhofer A. The effect of inline skating on postural control in elderly people. Dtsch Z Sportmed. 2010;61(2):45-51. 
34. Taube W, Gruber M, Beck S, Faist M, Gollhofer A, Schubert M. Cortical and spinal adaptations induced by balance training: correlation between stance stability and corticospinal activation. Acta Physiol. 2007;189(4): 347-58. doi:10.1111/j.1748-1716.2007.01665.x

35. Taube W, Gruber M, Gollhofer A. Spinal and supraspinal adaptations associated with balance training and their functional relevance. Acta Physiol. 2008;193(2): 101-16. doi:10.1111/j.1748-1716.2008.01850.x

36. Taube W, Kullmann N, Leukel C, Kurz O, Amtage F, Gollhofer A. Differential reflex adaptations following sensorimotor and strength training in young elite athletes. Int J Sports Med. 2007;28(12):999-1005. PubMed doi:10. 1055/s-2007-964996

37. US Department of Health and Human Services. Healthy People 2010. Washington, DC: US Government Printing Office; 2000.

38. Winter T, Beck H, Walther A, Zwipp H, Rein S. Influence of a proprioceptive training on functional ankle stability in young speed skaters-a prospective randomised study. J Sports Sci. 2015;33(8):831-40. PubMed doi:10.1080/ 02640414.2014 .964751 